de Gruyter Lehrbuch 



\section{Martin Honecker}

\section{Grundriß \\ der Sozialethik}

$\mathrm{W}$
$\mathrm{OE}$
$\mathrm{OE}$

Walter de Gruyter · Berlin · New York 1995 
(@) Gedruckt auf säurefreiem Papier, das die US-ANSI-Norm über Haltbarkeit erfüllt.

\section{Die Deutsche Bibliothek - CIP-Einheitsaufnabme}

\section{Honecker, Martin:}

Grundriss der Sozialethik / Martin Honecker. - Berlin ; New York : de Gruyter, 1995

(De-Gruyter-Lehrbuch)

ISBN 3-11-014474-3 brosch.

ISBN 3-11-014889-7 Gb.

(C) Copyright 1995 by Walter de Gruyter \& Co, D-10785 Berlin

Dieses Werk einschließlich aller seiner Teile ist urheberrechtlich geschützt. Jede Verwertung außerhalb der engen Grenzen des Urheberrechtsgesetzes ist ohne Zustimmung des Verlages unzulässig und strafbar. Das gilt insbesondere für Vervielfältigungen, Übersetzungen, Mikroverfilmungen und die Einspeicherung und Verarbeitung in elektronischen Systemen.

Printed in Germany

Satz und Druck: Arthur Collignon $\mathrm{GmbH}$, Berlin

Buchbinderische Verarbeitung: Lüderitz \& Bauer-GmbH, Berlin 